\title{
O mapa da saúde e o regime de visibilidade contemporâneo'
}

\section{Health maps and the contemporary visibility regime}

\author{
Érico Ibiapina ${ }^{a}$ \\ (D) http://orcid.org/0000-0002-1526-2084 \\ E-mail: erico.ibiapinaœusp.br \\ Anita Bernardes ${ }^{b}$ \\ (D) http://orcid.org/0000-0003-4742-6036 \\ E-mail: anitabernardes1909ळgmail.com \\ aUniversidade de São Paulo. Faculdade de Saúde Pública. São \\ Paulo, SP, Brasil. \\ bUniversidade Católica Dom Bosco. Campo Grande, MS, Brasil.
}

\section{Correspondência}

Érico Ibiapina

Av. Doutor Arnaldo, 715, Pacaembu. São Paulo, SP, Brasil. CEP 01246-904.

\section{Resumo}

Este artigo analisa a articulação entre território, acesso e tecnologias em saúde. 0 objetivo é colocar em análise o mapa da saúde a partir da relação entre regime de visibilidade e tecnologias de vigilância em saúde. 0 percurso da reflexão apoiase na problematização do georreferenciamento no campo da saúde para monitoramento e vigilância dos fluxos de circulação de pessoas no espaço urbano como estratégia biopolítica. A análise perpassa, portanto, a problematização de técnicas de mapeamento do campo da saúde para pensar formas de controle e regulação populacional como processos não naturais que permitem certas formas de articulação entre acesso, território e tecnologias em saúde. Deste modo, o artigo segue o itinerário: (1) analisa o território como um dos elementos que constituem um dispositivo no campo da saúde; (2) discute como a vigilância está implicada nas estratégias de mapeamento na saúde a partir dos primeiros mapas biossociais; (3) aborda a relação entre georreferenciamento e tecnologias de vigilância em saúde como estratégia biopolítica.

Palavras-chave: Georreferenciamento; Biopolítica; Saúde Pública.

\section{Abstract}

This article analyzes the articulation between territory, access, and technologies in health. The objective is to analyse the health map based on the relationship between visibility regime and health surveillance technologies. The course of reflection is based on the problematization of the use of

Fonte de financiamento: Coordenação de Aperfeiçoamento de Pessoal de Nível Superior (Capes) e Conselho Nacional de Desenvolvimento Científico e Tecnológico (CNPq). 
the georeferencing in the field of health for the monitoring and surveillance of people circulation flows in urban space as a bio-political strategy. The analysis, therefore, involves the problematization of mapping techniques in the health field to think of forms of population control and regulation as unnatural processes that allow certain forms of articulation between access, territory, and health technologies. In this way, the article follows the itinerary: (1) analyses the territory as one of the elements that constitute a device in the field of health; (2) discusses how surveillance is implicated in health mapping strategies from the first biosocial maps; (3) approaches the relationship between georeferencing and surveillance technologies as biopolitical strategy. Keywords: Georeferencing; Biopolitics; Public Health.

\section{Introdução}

Este artigo analisa a articulação entre território, acesso e tecnologias em saúde. Em razão disso, o objetivo é colocar em análise o mapa da saúde (Brasil, 2011a, 2011b) a partir da relação entre regime de visibilidade (Foucault, 1983) e tecnologias de vigilância na saúde. No artigo, o mapa da saúde (Brasil, 2011a) é problematizado como tecnologia que “acontecimentaliza” (Foucault, 1972) práticas em saúde pública e produz, dentre outros efeitos, novas possibilidades de pensar a relação entre território e acesso. A questão perpassa, portanto, o uso que o Estado faz de uma tecnologia de mapeamento em saúde para cartografar e normatizar aspectos da realidade. Participam dessa cartografia, em específico, agentes estatais, usuários, técnicos e profissionais da saúde.

A discussão não se centra na dimensão georreferenciada da saúde, mas perpassa a possibilidade de falar e ver a circulação populacional a partir de aspectos da realidade que se tornam visíveis por meio do mapa da saúde (Brasil, 2011a): trata-se de uma forma de refletir sobre a relação entre território, acesso e tecnologias em saúde de modo situado. Nesse sentido, problematizar a política pública de saúde a partir de uma tecnologia de visibilidade de um aspecto da realidade é pensar que efeitos são produzidos sobre o governo da vida. Ademais, tecnologias cartográficas de mapeamento já foram problematizadas em estudos como instrumentos de conhecimento e poder (Bruno, 2009; Harley, 2006; Kitchin; Dodge, 2007; Stassun; Prado Filho, 2012).

Para Harley (2006, p. 82), ao discutir o mapa como instrumento ideológico e as tecnologias de mapeamento como estratégias de conhecimento e de poder, afirma que "algumas implicações dos mapas podem se relacionar com atos de 'vigilância' especialmente relacionados com a guerra, propaganda política e a definição das fronteiras”. Nesse sentido, os mapas mostram mais do que simplesmente uma representação da realidade baseada na articulação entre múltiplas técnicas cartográficas: retratam uma ideologia que define tanto os elementos que comporão o mapa para produzir uma realidade, quanto seus usos (Harley, 2006). 
Em estudo, Kitchin e Dodge (2007) destacam aspectos críticos e teóricos para afirmar que a cartografia não simplesmente representa o mundo como um processo de revelação, mas cria/produz realidades. Tal perspectiva destaca que no processo de produção cartográfica incluem-se escolhas subjetivas para o uso de tais ferramentas no que se refere à elegibilidade daquilo que se tornará visível ou invisível no mapa. A discussão dos autores situa crítica à ontologia da cartografia no que se refere aos usos de tecnologias cartográficas para produção de conhecimento. Afirmam os autores que "maps are the product of technicity (made by tools) and they possess technicity (they are a tool themselves)" (p. 341).

A pergunta que disparou este artigo foi feita a partir do encontro com a saúde pública brasileira por intermédio de um mapa. Pensar o mapa como uma ferramenta que permite produzir um aspecto da realidade e orienta fluxos no campo da saúde é algo intrigante porque a representação/produção do espaço geográfico a partir de mapas, no âmbito da vigilância em saúde, carrega uma orientação de território sempre implicada em uma dimensão jurídico-política. Para Foucault (1984, p. 89), "território é sem dúvida uma noção geográfica, mas é antes de tudo uma noção jurídico-política: aquilo que é controlado por um certo tipo de poder". 0 problema tratado aqui não se refere diretamente à representação de um plano da realidade a partir de uma técnica de mapeamento em saúde, mas o que se torna visível com o mapa da saúde (Brasil, 2011a) quando se focaliza a articulação entre território, acesso e tecnologias em saúde.

Um regime de visibilidade consiste não tanto no que é visto, mas em como torna visível uma realidade a partir de jogos de poder (Foucault, 1983). Colocar em análise um elemento de um regime de visibilidade é interrogar como práticas, instituições, tecnologias e procedimentos estão articulados para produzir, enquanto efeito de conjunto, a regulação de uma população, engendrando um ponto de contato entre vida e política.

Esse tipo de prática de mapeamento está relacionada a certa modalidade de produção de verdade e auxilia não somente o campo da saúde, mas também a segurança pública, considerando aquilo que Bruno, Kanashiro e Firmino
(2010, p. 7) já pontuaram sobre os efeitos que o mapeamento georreferenciado do crime produz sobre a "reordenação dos regimes de visibilidade" na contemporaneidade. Stassun e Prado Filho (2012), por exemplo, analisaram estratégias de geoprocessamento como prática biopolítica, com o intuito de gerar grades de inteligibilidade para problematizar como o Sistema de Informações Geográficas (SIG) conseguem agregar gestão tanto do território quanto da população. Nesse caso, o SIG foi problematizado como base técnica de governo sobre a população: um sistema que permite cruzar informações para tomada de decisão e planejamento público.

Ademais, as tecnologias de visibilidade de acontecimentos da vida costuram o tecido populacional, funcionando como algo que torna visível um nível de realidade, ao mesmo tempo que é "invisível" o mecanismo que dá contornos à visibilidade. Uma tecnologia de visibilidade produz efeitos "como um olhar sem rosto que transforme todo o corpo social em um campo de percepção" (Foucault, 1983, p. 237).

Para responder ao objetivo proposto no artigo, o percurso da reflexão apoia-se na problematização do uso do mapa da saúde (Brasil, 2011a) para monitoramento e vigilância dos fluxos de acesso à saúde (regulação da circulação de pessoas no espaço urbano) e georreferenciamento dos casos em saúde no espaço urbano como estratégia biopolítica (Foucault, 2008a). A discussão situa o mapa da saúde (Brasil, 2011a) como elemento do regime de visibilidade contemporâneo (Foucault, 1983) a partir de um jogo de forças agonísticas que atuam sobre a regulação de fenômenos populacionais. Partindo de um modo de questionar foucaultiano, buscaremos destacar pontos relevantes para a problematização do mapa da saúde (Brasil, 2011a), que produz efeitos de visibilidade e vigilância da circulação populacional para o acesso à saúde.

Portanto, a discussão engendra-se na dimensão daquilo que um elemento de um regime de visibilidade contemporâneo produz sobre a minúcia do cotidiano da população, sua dinâmica e circulação, processos de mobilidade sobre o espaço urbano e fenômenos migratórios. Foucault (2008a, p. 143) empreende uma análise genealógica das práticas 
de governo que permitem certo modo de pensar a regulação da multiplicidade como um tipo específico de poder instaurado no século XVIII "que tem por alvo principal a população, por principal forma de saber a economia política e por instrumento técnico essencial os dispositivos de segurança". O campo de análise foucaultiano compreende, dentre outros elementos, pensar como se torna possível a regulação populacional a partir daquilo que Foucault conceitua como dispositivo de segurança (Foucault, 2008a) e biopolítica (Foucault, 2005, 2008a, 2008b).

Portanto, trazemos o mapeamento no campo da saúde para um movimento de pensamento a partir do ferramental teórico foucaultiano no sentido de pensar formas de controle e regulação da circulação populacional como processos não naturais. Primeiramente, o artigo situa usos e utilidades de tecnologias de geoprocessamento na saúde. Em seguida, analisa-se o território como um dos elementos que constituem o dispositivo de segurança (Foucault, 2008a) e discute-se como a vigilância está implicada nas estratégias de mapeamento na saúde a partir dos primeiros mapas biossociais. Após esse momento, problematiza-se a relação entre regime de visibilidade e tecnologias de vigilância em saúde com base no mapa da saúde (Brasil, 2011a).

\section{Contribuições do Sistema de Informação Geográfica e georreferenciamento na área da saúde}

Para prosseguir com a análise do mapa da saúde (Brasil, 2011a), é necessário esclarecer quatro termos como não sinônimos: mapa, mapeamento, SIG e georreferenciamento. Após essa primeira elucidação, exemplificaremos como essas tecnologias são aplicadas no campo da saúde.

O mapa é um instrumento cartográfico que codifica e representa um aspecto da realidade, composto por dois elementos fundamentais - a ordem geográfica e seu conteúdo (Harley, 20o6). Já o mapeamento, no sentido cartográfico, é compreendido como processo de construção de mapas no qual técnicas de topografia, geoprocessamento, SIG, códigos e signos são usados em combinação para a descrição objetiva da realidade. Todavia, enfatizamos que a análise empreendida aqui se debruça sobre a contemporaneidade dos produtos do mapeamento digital georreferenciado no campo da saúde.

Embora seja comum a utilização do conceito de geoprocessamento em referência ao SIG, ambos não são termos equivalentes. 0 geoprocessamento é uma tecnologia que desenvolve sistemas para coleta e tratamento de informações espaciais utilizando múltiplas metodologias e equipamentos (Rodrigues, 1987). Os SIG são técnicas de geoprocessamento de dados, e não um sistema de produção cartográfica. Nesse sentido, constitui-se enquanto recurso tecnológico que atua por meio de uma base de dados gráficos, auxiliando na distribuição espacial do problema. De acordo com Pina (1998, p. 126), os SIG:

Permitem reunir uma grande quantidade de dados convencionais de expressão espacial, estruturandoos adequadamente, de modo a otimizar o tratamento integrado de seus três componentes: posição, topologia e atributos, na execução de análises e aplicações gráficas. São compostos essencialmente por um sistema gerenciador de um banco de dados georreferenciados e permitem a realização de análises espaciais complexas através da rápida formação e alternação de cenários que propiciam a planejadores e administradores em geral, subsídios para a tomada de decisões.

Dentre os múltiplos usos e utilidades do mapeamento com auxílio do georreferenciamento e do SIG no campo da saúde, pode-se citar, por exemplo, a análise dos vetores de transmissão de doenças no espaço geográfico (Cotrim et al., 2017); o planejamento a partir de indicadores de acessibilidade física aos serviços de saúde pela população rural (Ferreira; Raffo, 2012); a análise das relações entre acessibilidade e mobilidade urbana (Ribeiro et al., 2015); a relação entre a distribuição geográfica de doenças com dados socioeconômicos e desigualdade em saúde (Negrão; Vestena; Borecki, 2017; Ribeiro; Silva, 2016); e a identificação de doenças e epidemias no espaço urbano (Almeida; Silva, 2018; Silva, 2017).

O SIG, no âmbito da saúde pública, utiliza-se da sobreposição de camadas temáticas para estudo 
do processo saúde-adoecimento em combinação com variáveis espaciais. O uso do SIG no campo da saúde também atravessa, de acordo com Pina (1998, p. 130-131), "análise na distribuição de pacientes, monitoramento da qualidade da água, variações na ocorrência de epidemias, monitoramento de vetores, avaliação em tempo real de situações de emergência ou catastróficas”.

\section{Figura I - Diagramação do uso de geoprocessamento de dados espaciais}

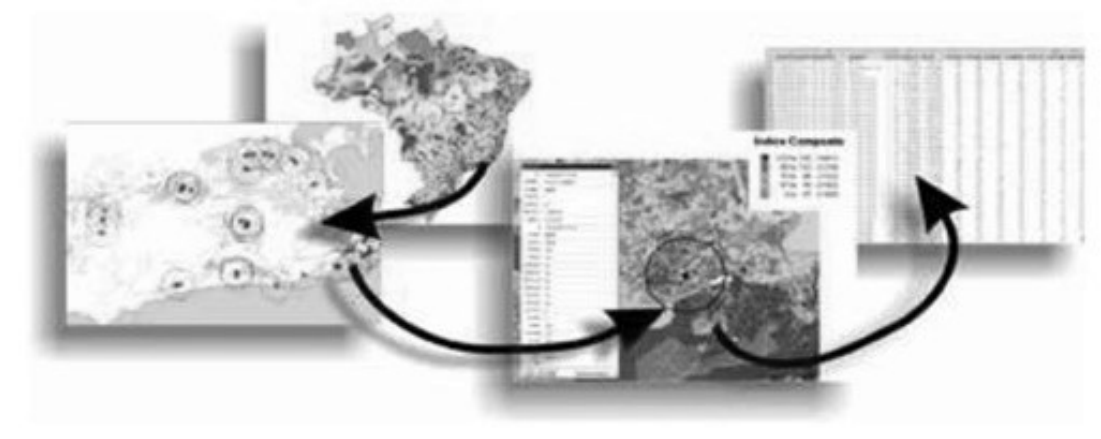

Fonte: Baluz, 2010

A análise de dados com o uso de tecnologias de georreferenciamento tem sido de grande auxílio no âmbito da saúde pública para o planejamento, gestão em saúde, vigilância e análise de dados socioespaciais. De acordo com Ferreira e Raffo (2012, p. 178), “a aplicação de conhecimentos de SIG no campo da saúde pública tem atendido dois propósitos: o das pesquisas científicas sobre a espacialização de doenças; e às necessidades de planejamento e gestão dos serviços". Conforme o Conselho Nacional de Secretários em Saúde (Conass), no que se refere ao mapa da saúde (Brasil, 2011a):

De acordo com o Manual de Planejamento no SUS do Ministério da Saúde, dois produtos compõem esta ferramenta: o GeoSaúde, que representa um sistema de georreferenciamento de dados, e a Análise em Saúde, que realiza a combinação e análise de informações a serem estruturadas segundo uma combinação de variáveis com o GeoSaúde, de modo a produzir informações para a tomada de decisões pelos gestores. (Conass, 2016)

Esse recurso tecnológico de mapeamento na saúde também permite o diálogo entre a estatística espacial, geografia e epidemiologia com aspectos da população que são dinâmicos, como sua circulação para o acesso à saúde e migrações nacionais/ internacionais. De acordo com Monken e Barcellos (2007, p. 218),

os mapas de saúde, que podem hoje em dia serem feitos com programas simples de geoprocessamento, permitem, entre outras funções, a comparação de taxas de incidência ou mortalidade em diferentes lugares, gerando hipóteses sobre causas. [...] Os fluxos de pacientes, do local de residência ao local de atendimento, podem ser visualizados por meio de mapas.

Apesar de o mapa da saúde ser regulamentado por legislação federal (Brasil, 2011b) que orienta o planejamento de saúde, não há um modo padronizado em operá-lo considerando as especificidades territoriais do país.

O mapa da saúde (Brasil, 2011a), enquanto instrumento desenvolvido para análise situacional de saúde, engendra-se no "processo de identificação, formulação e priorização dos problemas e das necessidades de saúde da população em um determinado território, orientando a definição das medidas a serem adotadas" (Brasil, 2016, p. 103). A análise situacional de saúde com o uso do mapa da saúde compreende o georreferenciamento com o uso 
de SIG a partir de um conjunto de dados divididos em oito tópicos: estrutura do sistema de saúde; rede de atenção à saúde; condições sociosanitárias; fluxos de acesso; recursos financeiros; gestão do trabalho e da educação na saúde; ciência, tecnologia, produção e inovação em saúde; e gestão (Brasil, 2016).

\section{Noção de dispositivo, território e a regionalização na saúde}

Pensar o mapa da saúde (Brasil, 2011a) em sua dimensão política é situá-lo como uma aposta da iniciativa pública para a regionalização do sistema de saúde (Brasil, 2001). Problematizá-lo como elemento de um regime de visibilidade é questionar como a circulação populacional torna-se visível a partir do mapeamento dos fluxos de acesso à saúde e de casos epidêmicos. Tal análise também logra um desdobramento de discussão já realizada (Ibiapina; Bernardes, 2018) sobre gestão de riscos a partir de tecnologias que figuram no âmbito político-jurídico da saúde pública.

Um dos elementos centrais que circundam a noção de território na analítica foucaultiana é o conceito de dispositivo. O dispositivo de poder congrega um conjunto de técnicas, procedimentos e instrumentos que geram como efeito a regulação da população. O dispositivo, portanto, enuncia certa modalidade de poder, tecendo uma rede que conecta "discursos, instituições, organizações arquitetônicas, decisões regulamentares, leis, medidas administrativas, enunciados científicos, proposições filosóficas, morais, filantrópicas" (Foucault, 1984, p. 138). O dispositivo refere-se ao entrelaçamento da técnica jurídico-legal, de técnicas disciplinares e de segurança para vigilância e controle do grão mais fino dos comportamentos populacionais, aquilo que atravessa a minúcia dos acontecimentos cotidianos.

As tecnologias de segurança, assim como as disciplinares, trabalham com multiplicidades. As primeiras regulam as multiplicidades a partir de seu próprio movimento, baseado em "uma determinada maneira de administrar a multiplicidade, de organizá-la, de estabelecer seus pontos de implantação, as coordenações, as trajetórias laterais ou horizontais, as trajetórias verticais e piramidais, a hierarquia” (Foucault, 2008b, p.16). O problema é a relação entre a tecnologia disciplinar do corpo e a tecnologia regulamentadora da população, ponto onde se cruzam a norma da disciplina e a norma da regulamentação.

Em meados do século XVIII, com a emergência do problema do crescimento populacional na Europa, a população aparece como elemento de centralidade para o governo, e aqui começam a aparecer as tecnologias de esquadrinhamento da população, como as estimativas demográficas, as taxas de mortalidade e natalidade e as estimativas de vida. As características do corpo populacional estão diretamente ligadas à administração e gestão econômica como condições fundamentais para garantir o bom estado de saúde da população e da economia do Estado.

Essas "tecnologias da população" emergem justamente por meio da aproximação entre estatística, Estado e governo da vida, instituindo a saúde pública como uma polícia do corpo social com a função de esquadrinhar a população e assegurar a ordem e o estado de saúde geral. Foucault (1984) exemplifica o movimento de emergência da medicina social em diferentes países da Europa e o relaciona com especificidades econômicas e políticas. A medicina social francesa organizou-se a partir de um "sistema de vigilância generalizada que dividia, esquadrinhava o espaço urbano" (p. 52). A emergência da medicina social na França ocorreu com base no processo de urbanização para pensar na melhor possibilidade de circulação de coisas e pessoas pelas cidades. Diferentemente de outras medicinas sociais - como a da Alemanha, que teve como foco a normalização da prática médica pelo Estado; e a da Inglaterra, que socializou o corpo como força de trabalho -, na França a medicina social instrumentaliza-se com tecnologias centralizadas de registro para vigilância das cidades, conhecidas como quarentenas no século XVIII (Foucault, 1984). Esse modelo médico e político esquadrinhava o espaço urbano com o objetivo de registrar, sob um comando de ordem centralizada, possíveis focos de doença nos bairros e casas.

Segundo Foucault (1984, p. 109), “a súbita importância que ganha a medicina no século XVIII tem seu ponto de origem no cruzamento de uma nova economia 'analítica' da assistência com a emergência 
de uma 'polícia' geral da saúde”. Esse cruzamento da economia analítica com a emergência de uma polícia da saúde criou condições de possibilidade para que a medicina com foco essencialmente fundamentado nos serviços de caridade pudesse ser operada pelo Estado por meio do esquadrinhamento do corpo populacional com o intuito de diminuir doenças e agravos à saúde da população.

Nessa perspectiva, a economia política aparece como a ciência que conduz a base técnica de intervenção na população, ou seja, racionaliza-se uma forma de governo traduzida nas instituições de Estado. Para Foucault (1984, p. 170), “apreendendo a rede de relações contínuas e múltiplas entre a população, o território, a riqueza, se constituirá uma ciência, que se chamará economia política”. Para operacionalização do cálculo das forças do Estado, atua-se com uma noção política de território em que a força do Estado não será proporcional à extensão territorial como no regime de dinastia, mas será proporcional ao que, a partir da objetivação de um aspecto da realidade, se torna visível em perfis epidemiológicos, estatísticas sanitárias, mapas da saúde, por exemplo.

A rigor, a análise foucaultiana dos mecanismos de segurança atravessa a atualização de tecnologias de poder soberanas sobre o território. Com a emergência dos mecanismos de segurança para o governo da multiplicidade no século XVIII, opera-se uma nova dinâmica do poder, que não sucede o poder soberano, mas lhe dá outros contornos, de modo a "fazer viver e deixar morrer" (Foucault, 2005 p. 287). 0 interessante é trazer esse ferramental teórico conceitual para a atualidade, de modo que o "deixar morrer" apontado por Foucault habita hoje na região de opacidade, naquilo que não se torna visível em nível de investimentos biopolíticos como os fluxos de acesso à saúde que são invisíveis no mapa da saúde (Brasil, 2011a).

Portanto, é questionando "os silêncios" existentes na forma de mapeamento georreferenciado do fluxo de acesso à saúde e dos casos epidêmicos (Brasil, 2011a) no mapeamento digital em saúde que interrogamos a região de opacidade da circulação populacional para acesso à saúde. Tal opacidade se materializa, por exemplo, na circulação de migrantes internacionais pelo espaço urbano para o acesso à saúde via organizações não governamentais (Santos, 2016).
Como já pontuado, a analítica foucaultiana não trata de uma sucessão de acontecimentos e técnicas, mas da atualização dessas técnicas em novas formas de operar mecanismos de poder na atualidade. Especificamente a noção de dispositivo de segurança, para Foucault (2008a), aparece como mecanismo essencial da governamentalidade, na medida em que a segurança trabalha com a normalização de uma realidade; ou seja, o objetivo é tornar regulável uma realidade a partir dos elementos que a constituem. De acordo com Foucault (2008a, p. 28):

Os dispositivos de segurança trabalham, criam, organizam, planejam um meio antes mesmo da noção ter sido formada e isolada. O meio vai ser, portanto aquilo em que se faz a circulação. 0 meio é um conjunto de dados naturais, rios, pântanos, morros, é um conjunto de dados artificiais, aglomerações de indivíduos, aglomerações de casas, etc. 0 meio é certo número de efeitos, que são efeitos de massa que agem sobre todos os que aí residem.

Pensar a noção de território no campo da saúde é atentar para a migração de uma concepção monocausal para uma concepção de saúde ampliada: na primeira, território era o meio no qual circulava um vetor de doenças; na segunda, o território aparece como meio por onde perpassam modos de viver de uma população. Nesse sentido, ao falar de território em saúde, é imprescindível reportar-se ao modo como esse conceito é operado a partir da diretriz política de regionalização (Brasil, 2001) do SUS como ação política que organiza o território no âmbito da saúde pública brasileira.

A regionalização (Brasil, 2001) dos serviços de saúde opera com uma multiplicidade de termos que objetivam o território, como distrito sanitário, município, estado, regiões de saúde, macrorregião, microrregião, área de abrangência, microárea de risco. Esses arranjos técnicos normativos traduzem as divisões administrativas em diversos níveis ou escalas que o Estado estabelece. Acerca do processo de territorialização em saúde, Pessoa et al. (2013) afirmam que a racionalidade territorial com que opera a política de regionalização dos serviços tem se reduzido a questões meramente administrativas no âmbito 
intraestadual, portanto, sem incorporar uma racionalidade territorial mais abrangente.

A Norma Operacional da Assistência à Saúde (NOAS) (Brasil, 2001), no que se refere à operacionalização da diretriz política de regionalização no sistema de saúde, cria o Plano Diretor de Regionalização (PDR), que focaliza o acesso ao sistema, levando em consideração o planejamento e o esquadrinhamento dos espaços urbanos de maneira a ofertar acesso ao cidadão "o mais próximo possível de sua residência” (p. 4). Ainda de acordo com a NOAS, “o processo de regionalização deverá contemplar uma lógica de planejamento integrado, compreendendo as noções de territorialidade na identificação de prioridades de intervenção e de conformação de sistemas funcionais de saúde" (p. 4). A diretriz política de regionalização circunscreve o que deve ser selecionado ou não para fazer parte da geografia dos espaços em saúde e aproxima o território das necessidades sociais de saúde da população, por meio das estatísticas de acesso ao sistema.

Nesse sentido, queremos mostrar como a diretriz política de regionalização em saúde torna possível pensar um aspecto da realidade que aproxima o território das condições de vida populacionais, ou seja, que aproxima a política do cotidiano da vida e possibilita, pelos meios necessários, operar, dentre outras tecnologias de gestão e planejamento em saúde, o mapeamento georreferenciado (Brasil, 2011b) dos fluxos de acesso e dos casos epidêmicos em saúde. Considerando, ainda, o que Bernardes e Marques (2016) já afirmavam sobre circulação populacional para acesso em saúde:

Esse meio social é a força que constitui a figura dos Estados modernos e, com eles, seus processos sociopolíticos de subjetivação, mediante os quais os problemas de saúde da população se tornam um acontecimento que permite pensar a circulação nos espaços das cidades, bem como os modos de controle e regulação dessa circulação. (p. 71-72)

Ademais, o território na saúde permite que as condições de vida da população adquiram um meio concreto para sua compreensão, vigilância, controle e investimento, definindo-se aquilo que está dentro e o que está fora de um coletivo que performa e intervém nas necessidades sociais de saúde. Pelo processo de tornar visível um território de práticas é possível fabricar uma superfície ótica para o próprio acesso à saúde.

Considerando que os textos de Foucault se apoiaram em certa literatura do período (ele escreve sobre a genealogia do poder no limiar da modernidade), apontamos algumas referências a autores contemporâneos que dialogam com o pensamento geográfico e a saúde. O conceito de território no campo da saúde é discutido por vários geógrafos, tais como: Monken e Barcellos (2005, 2007) e Haesbaert (2004). Uma das discussões contemporâneas sobre saúde e território a partir do conhecimento geográfico considera o uso e a apropriação do território por inúmeros agentes sociais (Monken; Barcellos, 2005; Monken et al., 2008 apud Guimarães, 2015, p. 89).

Ademais, o termo território está etimologicamente ligado a uma dupla conotação, tanto material quanto simbólica. De acordo com Haesbaert (2004, p. 1), a raiz da palavra território "aparece tão próximo de terra-territorium quanto de terreo-territor (terror, aterrorizar), ou seja, tem a ver com dominação (jurídico-política) da terra e com a inspiração do terror". O território em seu sentido funcional está relacionado a processos de dominação, recurso e valor de troca; já em sentido simbólico, refere-se a processos de apropriação (Haesbaert, 2004).

No campo da saúde, para Monken e Barcellos (2005, p. 898), há uma redução do conceito de território quando "utilizado de uma forma meramente administrativa, para a gestão física dos serviços de saúde, negligenciando-se o potencial deste conceito para a identificação de problemas de saúde e de propostas de intervenção”. Os serviços primários de saúde, por exemplo, são operacionalizados a partir de tecnologias de base territoriais, em que a tríade "serviço-território-população" (Monken; Barcellos, 2007, p. 212) se torna circunscrita ao planejamento em saúde, à capacidade de oferta de serviços e aos modos como a demanda de saúde é operacionalizada/georreferenciada no território.

\section{Mapeamento, vigilância e circulação}

A relação entre vigilância e técnicas de mapeamento atravessa os modos como se avizinham, 
no século XIX (Short, 2003), a estatística, a produção de mapas e as ciências humanas para tornar visíveis e analisar processos sociais nos espaços urbanos, o que caracteriza os primeiros "mapas biossociais" (Bruno, 2009). O processo de mapeamento e vigilância da população foi se desenvolvendo conforme o crescimento das cidades com a urbanização e imigração (Short, 2003).

Mapas de doenças e de crimes são produzidos no século XIX, configurando uma cartografia dos perigos e constituindo certa forma de tornar visíveis as mazelas sociais - a geografia das mazelas, que ganha novos contornos no século XX. Os mapas do crime, como assinalado por Bruno (2009, p. 6), demonstram "estatísticas morais", que atualmente:

se multiplicam segundo formatos sofisticados e renovados, cruzando imensas e variadas bases de dados, constituindo perfis de crimes e criminosos que levam em conta múltiplos fatores (educacionais, biométricos, econômicos, psicológicos, comportamentais, etc.) que se cruzam com dados geoespaciais.

Assim como o mapa do crime tornava visível uma realidade socioespacial, o mapa da doença do século XIX cruza aspectos sociais com focos de epidemia e variáveis espaciais, tornando possível um modo de visualizar a realidade sob a ótica da localização do perigo e da probabilidade do risco a partir da circulação de pessoas no espaço urbano.

O mapeamento produzido por John Snow (1955 apud Cameron; Jones, 1983), que se iniciou no contexto da medicina social, antecipa a "demonstração da teoria microbiana” (Almeida Filho, 1986, p. 306) com o uso de técnicas de mapeamento geográfico para analisar a disseminação de doenças no espaço urbano. 0 importante, ao citar Snow e seu trabalho, é atentar para o que estava pressuposto em seu mapeamento, assim como afirmam Cameron e Jones (1983, p. 394): "Snow não estava procurando associações, mas conectando cadeias causais”.

O modelo moderno de vigilância foi disseminado a partir dos trabalhos de William Farr no século XIX (Waldman, 1991), pela implantação de um sistema de coleta, centralização, análise e divulgação estatística. A vigilância emerge como um dos elementos de gestão de riscos enquanto procedimento, e contextualiza a problemática na medida em que também permite aproximar a população e a economia política (Foucault, 1984), marcando de forma específica relações de poder entre Estado e sociedade. O problema aqui em análise se produz a partir das técnicas políticas que constituem o que deve ser vigiado, analisado, centralizado e divulgado, engendrando uma racionalidade nas formas de operar um regime de visibilidade do esquadrinhamento populacional e de circulação de coisas e pessoas no espaço urbano.

O mapeamento georreferenciado em vigilância, por exemplo, permite o acompanhamento longitudinal dos casos em saúde pública e de sua distribuição espacial, expressos em mapas da saúde (Brasil, 2011a) que, por sua vez, traduzem hipóteses sanitárias sobre o processo saúde-adoecimento na comunidade. No mapa, "o mundo se oferece como paisagem e a invisibilidade do todo se inscreve na visibilidade do plano" (Bruno, 2009, p. 4).

$\mathrm{Na}$ análise dos dispositivos de segurança, Foucault (2008a) problematiza dois elementos que se tornam chave para o efeito de regulação populacional; são eles o meio e a circulação. A segurança dirige técnicas políticas sobre o meio onde se faz a circulação, sendo o primeiro qualquer elemento da realidade mediante o qual é possível circular uma ação. Para Foucault (2008a, p. 27), “o espaço próprio da segurança remete, portanto, a uma série de acontecimentos possíveis, remete ao temporal e ao aleatório, um temporal e um aleatório que vai ser necessário inscrever num espaço dado".

Com o recente uso de tecnologias de geoprocessamento de casos epidêmicos no âmbito da saúde pública, é possível pensar novas formas e estratégias de visibilidade que permeiam os processos de subjetivação da sociedade contemporânea e que, de certo modo, engendram "uma maneira de definir as relações do poder com a vida cotidiana dos homens" (Foucault, 1983, p. 228). O mapeamento por geoprocessamento na saúde utiliza a sobreposição de camadas temáticas para dar visibilidade a um aspecto de realidade, congregando dados estatísticos populacionais com dados geográficos e sociais, assim produzindo um tipo de mapa biossocial em que processos sanitários, sociais, econômicos, territoriais e políticos aparecem cruzados. A escolha 
das camadas desse mapa explicita as hipóteses do sistema de vigilância acerca de processos de saúde e doença a partir da combinação de variáveis. Por exemplo, de acordo com o Ministério da Saúde:

Colocar uma camada de estradas sobre uma camada de incidência de Aids pode evidenciar o papel destas estradas na difusão do HIV. Um mapa de uma camada de pontos de garimpo de ouro, sobreposta a outra camada com casos de intoxicação por mercúrio, pode ser útil para estudar-se a relação entre a emissão de mercúrio e os seus possíveis efeitos sobre a saúde. (Brasil, 20o6, p. 27)

As camadas temáticas que se sobrepõem no plano formado pelo georreferenciamento em saúde formam uma correlação entre processos sociais a partir da articulação de eventos de saúde (focos epidêmicos, casos de contaminação) com variáveis ambientais (saneamento básico, moradia) e sociais (processo saúde-adoecimento, desigualdade, pobreza) no que se refere ao perfil da população e ao acesso à saúde. Desse modo, a vigilância por meio do georreferenciamento focaliza determinados problemas populacionais e permite monitorar o comportamento de doenças relacionadas aos hábitos da população, ou seja, aquilo que a constitui como "conjunto de fenômenos naturais" (Foucault, 2008a, p. 473).

A estratégia de mapeamento por meio de técnicas de geoprocessamento em saúde, com a contribuição da ciência estatística, possibilita caracterizar tanto os espaços de acesso à saúde quanto as condições sociossanitárias, além de permitir a descrição de casos epidêmicos em saúde. Na Figura 2 podese verificar os resultados da análise de casos de dengue no espaço urbano a partir de técnicas de geoprocessamento.

\section{Figura 2 - Descrição por técnica de geoprocessamento em saúde acerca da (a) quantidade de habitantes em 2010 por bairros e (b) casos de dengue por bairros entre 2011 e 2014}

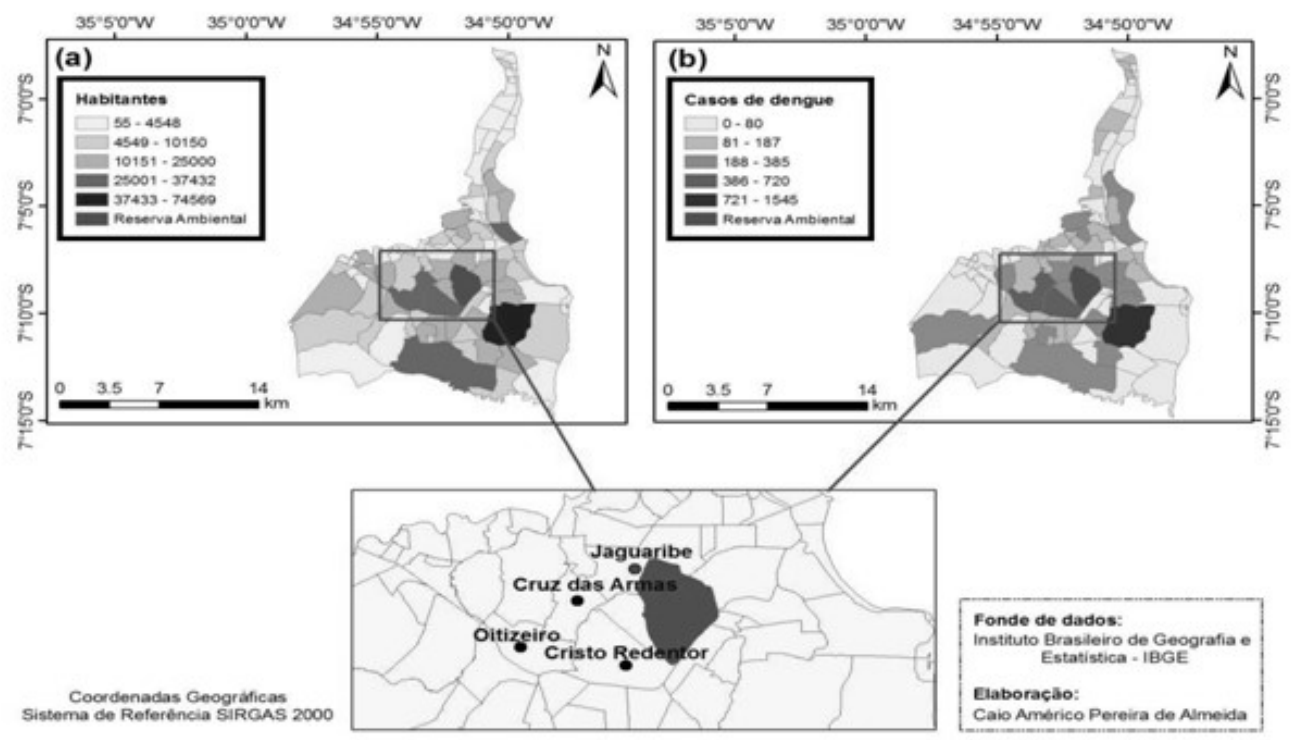

Fonte: Almeida; Silva, 2018

No que se refere ao mapeamento dos fluxos de acesso à saúde, o mapa "evidencia o caminho e distância percorridos pelos usuários, constituindo os fluxos assistenciais, mediante a apuração de residência e ocorrência de eventos" (Brasil, 2016, p. 104). O elemento circulação é um dos objetivos do mapa da saúde, aparecendo como fenômeno que compõe a probabilidade do caso (Ibiapina; Bernardes, 2018). Desse modo, ocorre a captura da ação pela mobilidade - e não somente captura, mas previsão do que pode acontecer, do aleatório. 0 problema é que o georreferenciamento 
dos fluxos em saúde engendra um mecanismo que converte pessoas em ações, e o espaço urbano em meio de circulação dessas ações, as quais se tornam visíveis pelo mapa e ao mesmo tempo engendra uma superfície de contato da política com a vida.

Os fluxos de circulação são capturados por tecnologias de vigilância e tornam-se cada vez mais regulados, produzindo coordenadas referenciais e fazendo atuar o mecanismo conhecimentointervenção em uma realidade (Foucault, 2008a). De acordo com Bruno (2009, p. 8), "nos mapas modernos, [...]. Tratava-se de radiografias sociais atreladas à produção de conhecimento e ao planejamento de intervenções públicas em larga escala”.

O mapa da saúde (Brasil, 2011b), em diferentes níveis de operacionalização do espaço, cria uma superfície, um aspecto de realidade para a própria política pública; ou seja, cria como efeito a estabilidade da política pública, com as intervenções em saúde sendo dirigidas para o plano que se torna visível com o mapa. 0 georreferenciamento, ao aproximar população e ambiente com base no processo saúde-adoecimento, possibilita a emergência da noção de risco social que assinala a vulnerabilidade populacional, e a focalização estratégica da saúde sobre a população, seu modo de vida, sua dinâmica de circulação, identificando quem são, como vivem e do que adoecem, inserindo fenômenos populacionais, em uma "série de acontecimentos prováveis" (Foucault, 2008a, p. 9).

A sobreposição de camadas temáticas do mapeamento em saúde (Brasil, 2011a), ao pressupor hipóteses sobre o processo de saúde-adoecimento de determinadas populações, também opera com a noção de encadeamento circular de causas e efeitos. Segundo Foucault (2008a, p. 28), no dispositivo de segurança a noção de meio perpassa "um elemento dentro do qual se faz um encadeamento circular dos efeitos e das causas, já que o que é efeito, de um lado, vai se tornar causa, do outro. Por exemplo, quanto maior a aglomeração desordenada, mais haverá miasmas, mais se ficará doente”. O meio, portanto, compreende o espaço por onde passa uma série de elementos aleatórios; é o "ponto de articulação entre elementos físicos com a espécie humana” (p. 3o).

\section{Regulação/vigilância da circulação populacional}

Seguindo a linha de problematização foucaultiana, com a modernidade foi possível pensar a criação de espaços perpassados por uma série de acontecimentos possíveis, a partir dos mecanismos de controle e gestão populacional. Esses acontecimentos se referem a um conjunto de fenômenos que dão densidade à noção de população, tanto como objeto quanto como alvo do governo, e marcam um ponto de contato da espécie humana com o governo da vida em sua dimensão regulamentadora. De acordo com Foucault (2005, p. 293), "são fenômenos aleatórios e imprevisíveis, se os tomarmos neles mesmos, individualmente, mas que apresentam, no plano coletivo, constantes que é fácil, ou em todo caso possível, estabelecer".

Arigor,o queécentral nojogo dagovernamentalidade não é o território propriamente, mas as estratégias que tornam o território uma potência agenciadora das formas de regular a população, de intervir em seus modos de vida. O regime de poder que caracteriza a governamentalidade relaciona-se não propriamente com o território, mas com "uma espécie de complexo constituído pelos homens e as coisas" (Foucault, 2008a, p. 128). São as formas de enunciação do território em regimes de visibilidade que permitem a produção de táticas para conhecer e regular o que habita e como habita; o que circula e como circula; o que faz parte e o que deixa de fazer parte da geografia dos espaços. Tal mecanismo de georreferenciamento aqui problematizado acontecimentaliza (Foucault, 1972) a saúde na contemporaneidade na medida em que permite que aquilo que antes era opaco (circulação local da população de sua residência para as portas de entrada da saúde pública) seja agora trazido para uma dimensão de visibilidade e regulamentação da vida (Foucault, 2005), relegando também outras possibilidades de acesso à saúde a uma região de opacidade.

O problema é como o movimento da população para acessar a saúde torna-se regulamentado, normalizado. Isso marca justamente o recorte de um nível de realidade em que a saúde é planejada de acordo com a previsibilidade das ações, o que normaliza também caminhos a serem percorridos, 
o movimento do corpo no espaço. Como afirma Foucault (2008a, p. 27), “a segurança procura criar um ambiente em função dos acontecimentos possíveis".

Trata-se de pensar o meio como espaço onde circula uma ação mediante o movimento de corpos e os modos atuais de conhecer-intervir nos acontecimentos da vida. A conversão de corpos em ações e a regulamentação dessas ações sobre as trajetórias "finitas” para o acesso à saúde que o mapa expressa, fazem funcionar a série: "população - processos biológicos - mecanismos regulamentadores - Estado” (Foucault, 2005, p. 298), compondo e afirmando uma relação inexorável entre vida e política.

Portanto, a "geovigilância" da circulação populacional no campo da saúde configura uma forma específica de operar uma mecânica do poder na contemporaneidade. A vigilância que transforma corpos em ações que circulam no espaço urbano visa à dimensão micropolítica do comportamento humano a partir da captura da circulação populacional no espaço, que se materializa, dentre outras formas, nos fluxos migratórios e na mobilidade urbana. Nesse sentido, o georreferenciamento da circulação populacional para acesso à saúde gera efeitos de massa, que dão substância ao conceito de população e seus fenômenos, operando "tecnologia em que os corpos são recolocados nos processos biológicos de conjunto" (Foucault, 2005, p. 297).

A estatística mostra-se como importante técnica, visto que, no campo do mapeamento georreferenciado em saúde, faz a circulação populacional funcionar em uma série de acontecimentos possíveis, tornando inteligível o pensar atrelado às condições ambientais e de vida de determinadas populações. O Estado, portanto, não estabelece uma relação de exterioridade com o corpo social, mas busca estratégias para se apoiar e justificar sua própria razão de existência a partir da regulação de elementos da própria realidade; ou seja, a população torna-se tanto sujeito de um poder regulamentador quanto objeto. Para Foucault (2008a, p. 27):

A segurança procura criar um ambiente em função dos acontecimentos possíveis, série que vai ser preciso regularizar num contexto multivalente e transformável. O espaço próprio da segurança remete, portanto, uma série de acontecimentos possíveis, um temporal e um aleatório que vai ser necessário inscrever em um espaço dado.

Ressalta-se que a geovigilância da saúde, por meio da relação entre circulação populacional no espaço urbano e gerência dos riscos, aparece como um problema que atravessa tanto a urbanização contemporânea quanto os modos de viver na cidade. O mapa da saúde (Brasil, 2011a) é, portanto, utilizado como instrumento para verificar as condições sanitárias de cada região e, então, planejar ações a partir do cruzamento de variáveis estatísticas e informações produzidas pelo geoprocessamento, pensando na melhor forma de circular pelo espaço urbano, no esquadrinhamento desses espaços, na previsibilidade dos riscos à saúde.

Em suma, o mapa da saúde, como uma tecnologia que produz visibilidades, permite (1) conhecer um aspecto da realidade, intervir nesse plano e sobre ele estabelecer operações; (2) operar tecnologias que enunciam verdades sobre a população e sua regulação; (3) inserir o fenômeno populacional em uma série de acontecimentos prováveis. 0 primeiro ponto refere-se, por exemplo, à invenção de um plano de realidade que torna possível operar mecanismos que oferecem densidade ao território na saúde e, assim, permitem intervir nos fluxos de circulação para acesso à saúde. 0 segundo ponto implica tornar viáveis, por meios necessários, os princípios e diretrizes que a própria política evidencia como demanda sobre um campo social, por exemplo, a objetivação das necessidades de saúde da população. O terceiro ponto relaciona-se com fazer funcionar fenômenos populacionais em uma série de práticas de governo, a partir da racionalização dos riscos como acontecimentos prováveis, considerando o modo de vida e a dinâmica de circulação da população no espaço urbano.

\section{O mapa da saúde e biopolítica: para prosseguir problematizando}

A problematização tratada aqui não atravessa quaisquer acontecimentos, mas aqueles que qualificam os modos de circulação e vida da 
população no espaço urbano, bem como as maneiras e técnicas que capturam a circulação dos corpos e seus rastros. Nesse sentido, é importante pensar a circulação/mobilidade humana como um problema que enseja uma crise global (Ventura, 2016). Considerando que a legitimidade do governo sobre a vida no campo da saúde está no fazer viver, o problema é produzido quando o mapa da saúde (Brasil, 2011a) entra nessa esteira das estratégias biopolíticas, trazendo para uma zona de opacidade outros movimentos de acesso à saúde e deixando morrer, assim, inúmeras outras possibilidades de vida. O problema, portanto, não é o mapeamento aparecer como uma prática biopolítica, mas o que se torna visível e invisível a partir do mapeamento georreferenciado na saúde.

Deste modo, problematizar a relação entre território e acesso à saúde por meio de uma tecnologia é circunscrever um campo de tensão das formas de governo da população. Esse jogo, que o próprio mapa produz, regula biopoliticamente a população e, portanto, o próprio acesso e os modos de circulação no território. Essa regulação permite que alguns elementos entrem em investimentos biopolíticos, enquanto outros são tornados opacos ou tampouco saem de uma região de opacidade.

Com isso se quer apontar que a noção de risco e sua necessária regulação, agenciada nessa articulação entre acesso, território e tecnologias em saúde, focalizam elementos interessantes para aquilo que se produz biopoliticamente, aquilo que entra na esteira das urgências a serem respondidas pelo dispositivo de segurança. Isso faz algumas formas de vida e de viver serem capturadas, pois entram no cenário do risco, enquanto outras desaparecem. 0 desaparecer da biopolítica não seria um problema, por si só, pois poderíamos pensar que se trataria de uma não captura, de um não assujeitamento; mas, nesse caso, se trata de formas de abandono da vida pelo não acesso a possibilidades de vida.

\section{Referências}

ALMEIDA, C. A. P.; SILVA, R. M. Análise da ocorrência dos casos de dengue e sua relação com as condições socioambientais em espaços urbanos: os casos de João Pessoa, cabedelo e bayeux, no estado da Paraíba - Brasil. Hygeia, Uberlândia, v. 14, n. 27, p. 56-79, 2018.

ALMEIDA FILHO, N. Bases históricas da epidemiologia. Cadernos de Saúde Pública, Rio de Janeiro, v. 2, n. 3, p. 304-311, 1986.

BALUZ, R. A. R. Geoprocessamento aliado à técnica de data warehouse como ferramenta para auxílio na saúde pública. Fepciência, Apucarana, v. 7, n. 10, p. 103-116, 2010.

BERNARDES, A. G.; MARQUES, C. F. Psicologia da saúde: articulações entre vida e política. Quaderns de Psicologia, Barcelona, v. 18, n. 3, p. 69-81, 2016.

BRASIL. Ministério da Saúde. Portaria no 95, de 26 de janeiro de 2001. Aprova a Norma Operacional da Assistência à Saúde. Diário Oficial da União, Brasília, DF, 26 jan. 2001.

BRASIL. Ministério da Saúde. Secretaria de Vigilância em Saúde. Fundação Oswaldo Cruz. Abordagens espaciais na saúde pública. Brasília, DF, 2006.

BRASIL. Ministério da Saúde. Planejamento do Sistema Único de Saúde. Brasília, DF, 2011a.

BRASIL. Ministério da Saúde. Decreto n ${ }^{0} 7 \cdot 508$, de 28 de junho de 2011. Regulamenta a Lei $\mathrm{n}^{\circ}$ 8.080, de 19 de setembro de 1990, para dispor sobre a organização do Sistema Único de Saúde - SUS, o planejamento da saúde, a assistência à saúde e a articulação interfederativa, e dá outras providências. Diário Oficial da União, Brasília, DF, 29 jun. 2011b.

BRASIL. Ministério da Saúde. Manual de planejamento no SUS. Brasília, DF: Fundação Oswaldo Cruz, 2016.

BRUNO, F. Mapas de crime: vigilância distribuída e participação na cibercultura. Revista da Associação Nacional dos Programas de PósGraduação em Comunicação E-compós, Brasília, DF, v. 12, n. 2, p. 1-16, 2009.

BRUNO, F.; KANASHIRO, M.; FIRMINO, R. Vigilância e visibilidade: espaço, tecnologia e identificação. Porto Alegre: Sulina, 2010. 
CAMERON, D.; JONES, I. G. John Snow, the broad street pump and modern epidemiology. International Journal of Epidemiology, London, v. 12, n. 4, p. 393-396, 1983.

\section{CONASS - CONSELHO NACIONAL DE}

SECRETÁRIOS DE SAÚDE. Guia de apoio a gestão estadual do SUS. Brasília, DF, 2016. Disponível em: <https://bit.ly/2H4yCj4>. Acesso em: $8 \mathrm{fev}$. 2018. Não paginado.

COTRIM, F. U. B. et al. Análise de casos de dengue nas grandes regiões e unidades federativas do Brasil com auxílio de sistema de informação geográfica. Revista Brasileira de Inovação Tecnológica em Saúde, Natal, v. 7, n. 1, p. 36-46, 2017.

FERREIRA, R. V.; RAFFO, J. G. O uso dos sistemas de informação geográfica (SIG) no estudo da acessibilidade física aos serviços de saúde pela população rural: revisão da literatura. Hygeia, Uberlândia, v. 8, n. 15, p. 177-189, 2012.

FOUCAULT, M. A arqueologia do saber. Petrópolis: Vozes; Lisboa: Centro do Livro Brasileiro, 1972.

FOUCAULT, M. Vigiar e punir: história da violência nas prisões. Petrópolis: Vozes, 1983.

FOUCAULT, M. Microfísica do poder. Rio de Janeiro: Graal, 1984.

FOUCAULT, M. Em defesa da sociedade. São Paulo, Martins Fontes, 2005.

FOUCAULT, M. Segurança, território, população. São Paulo: Martins Fontes, 2008a.

FOUCAULT, M. O nascimento da biopolítica. São Paulo: Martins Fontes, 2008b.

GUIMARÃES, R. B. Geografia da saúde: categorias, conceitos e escalas. In: GUIMARÃES, R. B. Saúde: fundamentos de geografia humana. São Paulo: Editora Unesp, 2015. p. 79-97.

HAESBAERT, R. Dos múltiplos territórios à multiterritorialidade. Porto Alegre: UFRGS, 2004.

HARLEY, J. B. La nueva naturaleza de los mapas. Cidade do México: FCE, 2006.

IBIAPINA, E. F. V.; BERNARDES, A. G. Vigiar e assistir: o território na atenção básica e a racionalização do acontecimento. Athenea Digital, Barcelona, v. 18, n. 3, p. 1-18, 2018.

KITCHIN, R.; DODGE, M. Rethinking maps. Progress in Human Geography, Thousand Oaks, v. 31, n. 3, p. 331-344, 2007.

MONKEN, M.; BARCELLOS, C. Vigilância em saúde e território utilizado: possibilidades teóricas e metodológicas. Cadernos de Saúde Pública, Rio de Janeiro, v. 21, n. 3, p. 898-9o6, 2005 .

MONKEN, M.; BARCELLOS, C. O território na promoção e vigilância em saúde. In: FONSECA, A. F. (Org.). O território e o processo saúde-doença. Rio de Janeiro: EPSJV/Fiocruz, 2007. p. 177-224.

NEGRÃO, G. N.; VESTENA, L. R.; BORECKI, M. T. Variáveis geográficas intervenientes na ocorrência da tuberculose pulmonar no perímetro urbano de Guarapuava, PR. Revista de Geografia, Juiz de Fora, v. 7, n. 2, p. 163-18o, 2017.

PESSOA, V. M. et al. Sentidos e métodos de territorialização na atenção primária à saúde. Ciência e Saúde Coletiva, Rio de Janeiro, v. 18, n. 8, p. 2253-2262, 2013.

PINA, M. F. R. P. Potencialidades dos sistemas de informações geográficas na área da saúde. In: NAJAR, A. L.; MARQUES, E. C. (Org.). Saúde e espaço: estudos metodológicos e técnicas de análise. Rio de Janeiro: Editora Fiocruz, 1998. p. 125-133.

RIBEIRO, H.; SILVA, E. N. Desigualdades intraurbanas em internações hospitalares por doenças respiratórias e circulatórias em uma área da cidade de São Paulo. Cadernos Metrópole, São Paulo, v. 18, n. 36, p. 461-479, 2016.

RIBEIRO, V. P. R. et al. Acessibilidade e SIG no planejamento em saúde: uma abordagem baseada em modelos de alocação-localização. Revista Portuguesa de Estudos Regionais, Angra do Heroísmo, n. 38, p. 1-16, 2015.

RODRIGUES, M. Geoprocessamento. 1987. Tese (Livre-Docência) - Escola Politécnica, Universidade de São Paulo, São Paulo, 1987.

SANTOS, F. V. A inclusão dos migrantes internacionais nas políticas do sistema de saúde 
brasileiro: o caso dos haitianos no Amazonas.

História, Ciências, Saúde: Manguinhos, Rio de Janeiro, v. 23, n. 2, p. 477-494, 2016.

SHORT, J. R. The world through maps. Richmond Hill: Firefly Books, 2003.

SILVA, M. C. Sistemas de informações geográficas na identificação de doenças e epidemias. Tekhne e Logos, Botucatu, v. 8, n. 4, p. 94-106, 2017.

STASSUN, C. C. S.; PRADO FILHO, K.

Geoprocessamento como prática biopolítica no governo municipal. Revista de Administração

Pública, Rio de Janeiro, v. 46, n. 6, p. 1649-1669, 2012.

VENTURA, D. Impacto das crises sanitárias internacionais sobre os direitos dos migrantes. Sur: Revista Internacional de Direitos Humanos, São Paulo, v. 13, n. 23, p. 61-75, 2016.

WALDMAN, E. A. Vigilância como prática de saúde pública. 1991. Tese (Doutorado em Saúde Pública) - Faculdade de Saúde Pública, Universidade de São Paulo, 1991.

\section{Contribuição dos autores}

Os autores contribuíram igualmente em todas as fases de composição do artigo.

Recebido: $25 / 04 / 2018$

Aprovado: 06/11/2018 